\title{
Understanding the Categories and their Natural Properties
}

\section{Abstract}

There are four ways of distinguishing theories or models about categories such as quantity, race and dis-ability and the relationship between mind and world. (i) Epistemic: a theory is superior to another because it has a better relationship with the world. (ii) The converse: a version of reality is superior to another because it contains fewer contradictions and disjunctions. (iii) The giving of reasons: some reasons and systems of rationality are superior to others. (iv) Pragmatic: a theory is better than another because it is more practically adequate. I suggest that a combination of all four reasons is appropriate.

\section{Keywords}

Qualitative analysis; world problems; categories; judgemental rationality; quantity; race; dis-ability; natural properties

\section{Resumen}

Existen cuatro formas de diferenciar teorías o modelos por categorías tales como: cantidad, raza, discapacidad y la relación entre mente y mundo. (i) Epistémica: una teoría es superior a otra debido a que tiene una mejor relación con el mundo. (ii) Lo contrario: una versión de la realidad es superior a otra porque posee menos contradicciones y disyunciones. (iii) Las razones aportadas: algunas razones y sistemas de racionalidad son superiores a otras. (iv) Pragmática: una teoría es mejor que otra porque es más adecuada en la práctica. Sugiero que es apropiada una combinación de las cuatro razones.

\section{Palabras clave}

Análisis cualitativo; problemas mundiales; categorías; racionalidad para juzgar; cantidad; raza; dis-capacidad; propiedades naturales

To cite this article / Para citar este artículo

Scott, D. (2018). Understanding the Categories and their Natural Properties. magis, Revista Internacional de Investigación en Educación, 11 (22), 33-42. doi: 10.11144/Javeriana.m11-22.ucnp 


\section{Introduction}

Philosophers often understand categories such as qualitative and quantitative to refer to the introspectively accessible, phenomenal aspects of our mental lives. In this broad sense of the term, it is difficult to deny that there are set categories that structure our thinking and ability to access the material world, which, consequentially, can be thought of as natural. Disagreement typically centers on which categories are intrinsic bearers of these qualities, and how they relate to the physical world. The status of the categories is hotly debated in philosophy largely because it is central to a proper understanding of the nature of consciousness and to the mindworld relationship (the principal relation in any attempt at understanding the world).

In the first instance there is a need to resolve the issue of whether a quantitative/qualitative, mixed methods approach (cf. Bryman, 2006; Burke-Johnson \& Onwuegbuzie, 2004) is credible. Three types of argument have been developed in support of this approach. The first of these is that the different paradigms that have traditionally been associated with qualitative and quantitative research approaches are in essence different epistemological approaches, and thus have little to do with the collection and analysis of empirical data. Knowledge and reality questions belong to a separate domain, and this is because empirical research is a practical activity, and in turn, this practical activity should be distinguished from philosophical pragmatism, an attempt to answer these knowledge and reality questions. Charles Sanders Peirce (1982) developed a pragmatic approach whose pragmatic maxim was that any theory of meaning, and thus of sense, takes as axiomatic that the contents of a proposition is the experienced difference between it being true or false. However, this philosophical pragmatic argument (and there are many compelling reasons for supporting such a position, which for reasons of space I cannot deal with here) cannot be equated with a pragmatic (understood in its ordinary language sense) position, which is that social researchers should not concern themselves with issues that are essentially the province of philosophers, those of how we can know the world (i.e. epistemology) and what this world is (i.e. ontology).

There are some problems with accepting this ordinary language pragmatist position. Researchers are committed to finding out about what is happening in the world, and thus to formulating credible accounts of what the world is like and how they can know it. In addition, they are preoccupied with issues of truth (expressed in the first instance epistemologically and in the second instance ontologically) and thus to what it is. Five different types of truth have been identified: truth as correspondence, truth as coherence, truth as what works, truth as consensus and truth as warranted belief (cf. Bridges, 1999). Regardless of which one is chosen, the researcher is still committed to a notion of research that is more than a pragmatic exercise in resolving practical and ethical problems in the research process.

A second argument for resolving the qualitative and quantitative divide is an acceptance that qualitative and quantitative methods and approaches are underpinned by different epistemological and ontological philosophical positions, but these different philosophical positions are not as different as they appear to be (cf. Haack, 2008). And what follows from this is that these differences can be resolved. There are two variants of this argument. The first is that, in contrast to positivism and empiricism, the elements or constituents of the world can be expressed as variables 
(a pre-requisite of quantitative methodologies) and consequentially, should not be treated as facts but as 'ficts' (cf. Olsen \& Morgan, 2004), expressed in a numerical form. These may not be true representations of the world, but they can act as devices for making inferential arguments about the world. A second variant of this argument is that intensional idioms, used by qualitative researchers because they refer to the intentions of human beings, can be reconfigured as extensional expressions. As a result, they refer to the extensional properties of the categories, such as breadth, depth, time-sequencing and positionality. This means that intensional idioms can be expressed in extensional forms, and can therefore satisfy the requirements for successful quantification. This is the false duality argument, and what it seeks to do is resolve the divide between what some have described as irreconcilable paradigms. However, this creates a semantic deficit, as this is essentially a reductionist exercise.

A third argument, which is an attempt to resolve the division between qualitative and quantitative methods and approaches and therefore sanction the development of a coherent mixed methods framework, is a warranty through triangulation framework. Here, instead of suggesting that the qualitative element, for example, can be translated into something that fits the quantitative element, as in our second argument, or that the researcher shouldn't concern themselves with philosophical issues as in our first argument, this argument accepts that both quantitative and qualitative approaches have different epistemic and ontological bases. If both are focused on the same research problem and similar conclusions are drawn, then the researcher can have a greater degree of confidence in their findings. However, if disparate conclusions are drawn, then clearly that confidence becomes misplaced.

What I want to suggest is that in the first instance, researchers are committed to some notion of the truth and that this commitment is determined by the adoption of credible ontological and epistemological stances. Researchers are in the business of developing knowledge and this means that they also have to have some understanding of what this knowledge is and what it refers to. A justification for the results of an investigation in the world, and thus for the relations between mind and world is that if categories and the relations between them can be shown to be natural, then they are also not constructed in any meaningful sense, and therefore they can be thought of as having a measure of credibility.

\section{Natural Kinds}

Two examples of social categories, which have important consequences in Latin American countries and other countries round the world and which are sometimes thought of as natural kinds, are dyslexia and race. With regards to dyslexia, two strands of thinking can be identified: the first refers to a general incapacity and the second focuses on 'particular processing functions that are significantly discrepant in relation to an individual's other processing abilities' (Reid, 2011, p. 153). These might include:

coordination difficulties; hyperlexia (low comprehension but good decoding skills); language and communication difficulties; dyslexia; auditory processing difficulties; hyperactivity; attention difficulties; dyscalculia; working-memory difficulties; information-processing difficulties; non-verbal difficulties; literacy difficulties; phonological processing difficulties; visual difficulties; social awareness difficulties (ibid.) 
Many of these specific learning difficulties can be placed on a continuum, and in addition, the existence of one specific learning difficulty does not preclude the existence of another, for example, a pupil can be diagnosed with dyslexia and hyperlexia.

Definitions of these terms have proved controversial. There appears to be no agreed scientific basis for differentiating between someone who has been diagnosed as dyslexic, someone who has been diagnosed as a poor reader (this may of course refer to someone who is disinclined to learn) and a general reader. Dyslexia itself can be understood as a general term to refer to almost any form of reading, decoding and spelling difficulty. This all-embracing term, in its broad inclusivity, then becomes so general that it is not particularly useful for developing remedial programmes. However, it may satisfy a need to know the condition that is afflicting someone, even if it doesn't in any way lead to an amelioration of the problem, with the problem being understood in normative terms so that a comparison can be made with a notional idea of how that learner should be behaving.

The concept of race can signify a division of people into different groups. (This is only one way it can be used.) Under this conception, races are said to have some type of biological foundation, and this generates discrete racial groupings, so that members of each group share a set of biological characteristics that are not shared by members of other groups. These characteristics are inherited from other members of the same racial grouping; and it therefore becomes possible to identify the geographical origin of each race. These inherited characteristics are usually thought of as physical phenotypes, such as colour of hair, skin colour, eye shape and bone structure; however, and this is where it becomes much more complicated, sometimes these characteristics are used to refer to behavioural phenotypes such as intelligence or criminality. For example, in 1735 Carl Linnaeus divided human beings, Homo Sapiens, into four distinct groupings, Europaeus, Asiaticus, Americanus and Afer, and associated each of them with a different humour or personality type, sanguine, melancholic, choleric and phlegmatic, respectively (cf. Anderson, 2009). Indeed, he described the first of these groupings as 'active, acute and adventurous', and the last of these as 'crafty, lazy and careless'.

James Watson, who discovered with Francis Crick, Rosalind Franklin and Maurice Wilkins, the double-helix structure of DNA, claimed in 2007 that black people were less intelligent than white people and that the idea of all racial groups sharing common and equal powers of reason was a delusion (cf. Guardian, December 1st, 2014). It is fairly easy to see that a belief in the concept of race as it is understood and defined here leads to certain social and political practices that discriminate against particular people; and in addition, that categories such as race, and subsequently the development of social and pedagogical practices associated with them, are not fixed in an essentialist sense and can be changed. Consequently, they cannot be thought of as natural kinds.

\section{The Structuring of the Discourse}

A discourse is a set of propositions about the world joined together by a set of connectives and relations that offers an account of an object or objects in the world, and may even act to create objects in the world. It can have a material form, that is, it can be written, orally presented or stored electronically as text, and is usually mediated through a language or languages. Implicit within every discursive formation are: a propositional 
account of a person, including their emergent capacities and affordances, and the environment within which they are situated; a propositional account of the relationship between a person and their environment; propositional knowledge about understanding, learning and change, with regards to the person and the environments in which they are located; inferences from these premises and conclusions about appropriate representations, media for representations and learning environments; and a set of practical actions that emanate from these claims. However, what needs to be said time and time again is that a discursive construction can never be a simple determinant of identity, behaviour or action. Discourses are structured in a variety of ways, and both this meta-structuring and the forms it produces are relative to time and place. These meta-forms refer to constructs such as generality, performativity, reference, value, binary opposition, representation and legitimacy.

The first of these, generality, is the designation of objects as separate from other objects in the world; in part, this constitutes a naming process and it refers to the relations between singulars and generalities. This refers to that which constitutes those items within a general description of a set of objects, such as quantitative/qualitative, abled/dis-abled and black/white.

A second meta-form concerns the balance in educational and social statements between denotation and performativity, or between offering an account of something with no intention of changing the world and offering an account which is intended to change an object or create a new one. These are performative statements. There is of course no guarantee that performative statements will in fact achieve their purpose. Denotative statements have a different function, in that they seek to describe what currently exists, what might exist in the future and what has happened in the past. The intention of the utterer is not to bring anything into being in the world. This distinction between performativity and denotation only makes sense if we consider the intentions of the maker of the utterance and in addition, the perceived relationship between statement and act; in other words, it implies such a relationship exists even if it does not specify what that relationship is. Educational and social statements in relation to categories, such as race, dis-ability then may be characterised in terms of the balance of performativity and denotation within them.

A third meta-epistemic form concerns the relative value given to an object in comparison with another object. For example, within a race discourse, one of the pair of words is given a greater value than the other, with a fairly obvious example being that white is privileged over black.

The fourth meta-structuring device refers to the bipolarity of objects, descriptions and dispositions, or hierarchically binary oppositions; that is, an object, description or disposition is defined in terms of another object, description or disposition of which it is the mirror opposite. If the black/white binary is used as an example, it is possible to see that the positioning of the two terms as oppositional in meaning, and the subsequent valuing of one (white) and the devaluing of the other (black) because of their oppositionality, has significant implications for the way the debate about relations between the two concepts can be conducted. Thus certain words, phrases, descriptors and concepts are understood in bi-polar terms, which determine how they can be used as a resource for understanding the world.

A fifth meta-principle refers to the referential value of a statement. Making an educational or social statement implies that a particular type of truth-value is being invoked. So, for example, a correspondence theory represents the truth of whether the statement mirrors the reality that it 
seeks to describe. A number of such theories are in existence, some fairly primitive such as naïve appeals to facts, others more sophisticated so that they avoid mirror imagery and at least take account of skeptical arguments. On the other hand, coherence theories argue that the truth-value of a statement does not lie in its reference to an external world but in whether it fits coherently in a web of knowledge. An educational statement about one or more of the categories therefore implicitly or explicitly is underpinned by a theory of reference embedded within a theory of truth, and this marks it out as a knowledge form.

A sixth meta-principle refers to the way the particular ideas, concepts, phrases, descriptors are embedded in networks of ideas, concepts, phrases and descriptors, and have a history. So, for example, dis-ability as a concept is always positioned in a bewilderingly complicated network of other terms, such as innateness; trait theory; genetics; biology; historical origin; evolutionary theory; cognitive, developmental, intellectual, physical and sensory impairment, and many more.

I have been referring here to the relations in the discourse between different ideas and notions, and how these can vary depending on the discourse. These relations are those of: generality, balance of performativity and denotation, relative value, hierarchical binary opposition, representation and legitimacy (cf. Scott, 2008). Each of these in turn can vary in relation to any of the others. Societies are different because different valuations are given to each of them.

Strong constructivists deny that there are any natural divisions or differences between objects, social or otherwise. They argue that the similarities and differences between objects can only be attributed to the social function of the relevant concepts and not to any natural processes. However, the problem is that the social functioning of concepts and the social functioning of practices in the world that have been influenced by these concepts are what constitutes the world and therefore are real. The problem relates to the definition of the natural. If the natural is understood as a pre-conceptualised (before human beings have activated the world) state of being, then the issue arises as to how far one should go back in history before one identifies a cut-off point between the natural and the non-natural. A conceptual division is established by the concrete actions of human beings; a boundary point is established at the conceptual level, which is neither natural nor non-natural. It is simply real. The principal argument made by constructivists is that any activity in and about the world is dependent on a human being or a number of human beings acting in the world, and this applies as much to concept-development as it does to other worldly practices.
Louis Dupré (1993) argues for a promiscuous realism, where the claim is made that there are countless ways of describing the world and for our purposes here of dividing up the world into different categorical forms; in other words, there are no criteria in the world or that could be a part of the world to allow us to say that one of these categorical frameworks is superior to another categorical framework. Natural differences between kinds are the boundaries between real entities. I have been dealing here with relations between different manifestations of an object over time.

Instead of talking about similarities and differences, perhaps we should be talking about the development of and genesis of how those differences and similarities were formed. What this implies is that similarities and differences that we understand and formulate at the epistemological level are not merely descriptions of kinds and thus boundaries between objects in nature but enter into a causal relation and thus have causal effects.

If there are no natural kinds either as prior to human activity or as a result of human activity then first, all kinds are in some degree constructed by and through the activities of human beings in history; second, their construction depends in some measure or another on the way one set of human beings behave towards another; and third, if those kinds are capable of reformulation then they are also capable of re-reformulation. The process of classification changes the nature of that object.

This is how we can begin to understand the difficult and contentious category of the qualitative/ quantitative. All references to the world involve the identification, manipulation and theorization of the categories, and we cannot avoid this. The scientific method, with its claims for the possibility of positional objectivity, concepts being reduced to measurable constructs, and the adoption of a representational ontology, is negligent of these.

\section{A Qualitative Methodology}

This meta-theory (sometimes referred to as a critical realist meta-theory) can be understood at the levels of strategy and method as a series of steps or action-sets (cf. Bhaskar, 1998). The first entails a process of reasoning and analysing laws that point to causal relationships as expressions of the tendencies of natural and social objects. The second is resolving a concrete event occurring in a context into its components. The third is re-describing the components in theoretically significant ways. The fourth is a retroductive move or moving from describing the components of an event to proposing explanations about what produces or are the conditions for the event. The fifth is eliminating 
alternative possible explanations. The sixth is identifying explanatorily crucial explanations. The seventh is correcting earlier proposed explanations in the light of the temporarily completed analysis. And finally there is a need to explain the parameters of these subsequent explanations and how they relate to the ontology and epistemology of the world.

The third of these action-steps is perhaps the most important. A concept is always embedded in a framework of other concepts, and that when we talk about the detheorisation of research what we are talking about here is that traditional and reductionist forms of research separate out the concept from the framework, in order for it to have the properties of a variable. Having detheorised the concept relations are then identified between these different variables, even if the variable itself does not enter into a meaningful relationship with the world. So, for example, as I have already indicated, race as a concept is always positioned in a complicated network of other terms, such as innateness, trait theory, genetics, phenotypicality, biology, historical origin, evolutionary theory and many more, and if we are to use this concept in the world then we have to give due consideration to this network of other ideas.

In the first instance then, educational researchers need to examine a range of phenomena. The first of these - structural properties at each time point - may or may not have been activated in the particular circumstances, but provide access to understanding the essential contexts of action. In doing this, researchers need to try to understand a second phenomenon -interpretations of those relations by relevant social actors. Data needs to be collected about these interpretations because they provide access to those interpretations and their effects. Instead of assuming that a structural property (in both non-discursive and discursive forms) always operates to facilitate human actions and interactions at every time point, it is important to understand when, where and how these different structures are influential; and furthermore, what the precise relationship is between them at specific moments and places during these interactions.

Researchers therefore need to gather data on those relations between different structures at each time point, and those perceived relations between different structures at each time point by the relevant social actors. This is a necessary part of the research process for two reasons. First, it provides access for the researcher to those real relations referred to above. Second, social actors' perceptions of those relations constitute a part of them. By examining their intentions, it is possible to make a judgement about how much they know and how this impacts on decisions they make.
Educational and social researchers also need to consider the unintended consequences of actions. Some activities may be designed, and thus have a degree of intention behind them, which may change those structural properties; others less so. But more importantly, all actions have unintended consequences to some degree. After each interaction, however limited, its effects on those structures that provide the contexts for future exchanges and interactions, need to be assessed. This last requirement for research therefore refers to the subsequent effects of those intended and unintended actions on structural properties. Finally, there is the focal point of any investigation: the degree of structural influence and the degree of agential freedom for each human interaction. This is the crux of the matter because it allows the researcher to understand the complex relationship between agency (i.e. the willed actions of players in the game) and structure (i.e. those conditioning factors that work on agency in the world) at each time point.

What I have suggested here applies to education as much as it does to other social areas for investigation. Steering a path between voluntarism and reification (i.e. the two dominant sociological perspectives that have been developed) in education is always problematic; but if it is to be successfully achieved, then, firstly, a coherent meta-theory needs to be articulated and enacted, and secondly, reifying and de-historising structural forms needs to be avoided, as this leads to a distortion and misunderstanding of social life and educational matters.

\section{Judgemental Rationality}

Judgemental rationality (cf. Bhaskar, 1998) then is the key idea and not the natural necessity of objects in the world, though the way that objects become the objects they are, and the relations between these objects as they are and as they will be, needs to be explained. This then also requires a theory of knowledge. A number of arguments have been put forward, which attempt to explain why one theory is better than another, and indeed whether this judgement in principle can be made. The first of these is that there are real issues which impact on our lives and it is these real issues that determine the truthfulness of particular theories. This is an argument in support of ontological realism but it doesn't take us very far in establishing whether it is possible to determine that one theory is better than another. However, what it does do is indicate that one of our criteria for this determination is the referent of knowledge (indeed that knowledge does have a referent). This is an important step in the argument for judgemental rationality (our ability to decide that one theory is better than another 
when they are both focused on the same area of social life), but it is not sufficient in itself to establish categorically that it is possible.

The most promising argument in favour of judgemental rationality is that once it has been established that there is a real world separate from our knowledge of it, then what follows from this is that there has to be a relation/connection between knowledge development and the world (not in a correspondence or representational sense). This argument rests on the foundational claim that knowledge is not the same as and is different in some important respects from what it claims to be about, i.e. its referent. This means that it then becomes possible to produce knowledge of this connection/relation and of the world itself, even if it is indirect. If it becomes possible to show how the process might work, then we can initiate the activity of grounding our theories in the world as it is and thus establishing in part the truth-capacity of claiming that one theory is better than another. This is the epistemic claim, where accounts of the world are more truthful because they have a better relationship with and to the world. However, this can only be established retroductively. (There is a process involved in knowing the world, sensate experience only takes us so far.)

Another argument is that if one theory can explain more significant phenomena than another can, then it is a superior theory. Explanatory power is understood as relative to the disciplines or fields within which the object of the investigation is situated. However, this doesn't mean that this can amount to the discovery of an ultimate truth. Clearly, if there are anomalies, contradictions or inadequacies in a theory, then it becomes possible for us to argue that this theory is inadequate or insufficient. So in trying to determine whether it is possible to establish that one theory is superior to another then we also (in addition to our epistemic criterion) have to build in a notion of rational adequacy. And what this implies is that the use of an imminent critique (i.e. critiquing a perspective in its own terms) to establish the possibility of deciding that one theory is superior to another theory means that the judgemental process is always internal to a tradition, disciplinary form of knowledge or particular framework. Thus, this criterion is also concerned to establish adequacy as only possible within a discipline or field. However, once again this seems to rule out the possibility of any form of universal or foundational knowledge. Denying the possibility of universals seems to be a contradiction in itself, since the denial acts in all important respects as a universal. If we accept this argument then we are beginning the process of accepting the existence of what Peter Strawson (1959) called universals of coherent thought, and even some universals relating to ontological relationships such as a mind-world distinction and consequently a connection between them.

A further argument refers to Jürgen Habermas' (1981) notion of communicative competence. The argument would then be that a theory is superior to another because in its production it better conforms to the rules for communicative competence. That is, any claim to theoretical credibility must be able to make the following assertions: this work is intelligible and hence meaningful in the light of the structuring principles of its discourse community; what is being asserted propositionally is true; what is being explained can be justified; and the person who is making these claims is sincere about what they are asserting. These four conditions if they are fulfilled allow a theorist to say something meaningful about the world. However, since we are trying to establish whether it is possible to determine that a theory is superior to another theory, then we cannot use the argument that our first theory is superior on the 
grounds that the supporter of this theory is coming from a better or purer position than the supporter of the other theory, because this assumes that the argument being made is necessarily right.

It is suggested that another way of determining whether a theory is superior to all other possible theories about the same social object is to make the claim that it is more powerful and has more powerful effects than these other theories. Self-evidently, some theories are more powerful or have more powerful effects in the world than others; however, this cannot provide us with an argument that might suggest that it is possible to say that one theory is a better theory qua its theoretical adequacy than another.

What are we left with? There are four ways of distinguishing between different theories or models. The first is epistemic: a theory is superior to another because it is more empirically adequate. The second is the converse, so that a version of reality is superior to another because it contains fewer contradictions and disjunctions. A third approach focuses on the giving of reasons, and concludes that some reasons and systems

of rationality are superior to others, and therefore should be preferred. A fourth approach is pragmatic: a theory is better than another because it is more practically adequate or referenced to/part of extant frameworks of meaning. A combination of all four reasons is, I suggest, appropriate.

\section{About the author}

David Scott is Emeritus Professor of Curriculum, Pedagogy and Assessment at the Institute of Education, University College London. His most recent books are: Equalities and Inequalities in the English Education System, London: University College London Institute of Education Press; and Education Systems and Learners: Knowledge and Knowers, London: Macmillan Palgrave.

\section{References}

Anderson, M. (2009). Carl Linnaeus: Father of Classification (Great Minds of Science). New Jersey: Enslow Publishers.

Bhaskar, R. (1998). General Introduction. In M. Archer, R. Bhaskar, A. Collier, T. Lawson \& A. Norrie (eds.). Critical Realism: Essential Readings, ix-xxiv. London, New York: Routledge.

Bridges, D. (1999). Educational Research: Pursuit of Truth or Flight into Fancy? British Educational Research Journal, 25 (5), 597-616. https:// doi.org/10.1080/0141192990250503

Bryman, A. (2006). Integrating Quantitative and Qualitative Research: How is it done? Qualitative Research, 6 (1), 97-113.

Burke-Johnson, R. \& Onwuegbuzie, A. (2004). Mixed Methods Research: A Research Paradigm Whose Time Has Come. Educational Researcher, 33 (7), 14-26.

Dupré, L. (1993). Passage to Modernity: An Essay in the Hermeneutics of Nature and Culture. New Haven, Connecticut: Yale University Press.

Guardian Newspaper, December 1' 2014.

Haack, S. (2008). Putting Philosophy to Work: Inquiry and Its Place in Culture. London: Prometheus Books.

Habermas, J. (1981). Theory of Communicative Action, Volume One: Reason and the Rationalization of Society. T. McCarthy, transl., Boston, Massachusetts: Beacon Press.

Olsen, W. \& Morgan, J. (2004). A Critical Epistemology of Analytical Statistics: Addressing the Sceptical Realist. Paper presented to the 
British Sociological Association, York, March 2004. Available at: https:// onlinelibrary.wiley.com/doi/abs/10.1111/j.1468-5914.2005.00279.x

Peirce, C. S. (1982). The Essential Peirce, two volumes. N. Houser, C. Kloesel \& The Peirce Edition Project (eds.). Bloomington, Indiana: Indiana University Press.

Reid, G. (2011). Dyslexia: A Practitioner's Handbook. Chichester: Wiley-Blackwell.

Scott, D. (2008). Education, Epistemology and Critical Realism. London, New York: Routledge.

Strawson, P. (1959) Individuals: An Essay in Descriptive Metaphysics. London: Methuen. 